\title{
BMJ Open Social capital and the health of left- behind older adults in rural China: a cross-sectional study
}

\author{
Yan Ke, ${ }^{1}$ Junfeng Jiang (D) , ${ }^{2}$ Yu Chen ${ }^{1}$
}

To cite: Ke Y, Jiang J, Chen Y. Social capital and the health of left-behind older adults in rural China: a crosssectional study. BMJ Open 2019;9:e030804. doi:10.1136/ bmjopen-2019-030804

- Prepublication history and additional material for this paper are available online. To view these files, please visit the journal online (http://dx.doi. org/10.1136/bmjopen-2019030804).

Received 02 April 2019 Revised 21 October 2019 Accepted 25 October 2019

D Check for updates

(c) Author(s) (or their employer(s)) 2019. Re-use permitted under CC BY-NC. No commercial re-use. See rights and permissions. Published by BMJ.

${ }^{1}$ School of Literature, Law and Economics, Wuhan University of Science and Technology, Wuhan, China

${ }^{2}$ School of Health Sciences, Wuhan University, Wuhan, China

Correspondence to Dr Junfeng Jiang; jiang0111@whu.edu.cn

\section{ABSTRACT}

Objective To examine the association between social capital and the health of male and female left-behind older adults in rural China.

Study design This cross-sectional study among the leftbehind older adults aged 60 and older and with all their children working outside of Hubei, Shaanxi and Guangdong provinces in China was conducted in 2017-2018. A total of 1106 questionnaires were collected (participation rate $=100.0 \%$ ), and questionnaires from 1016 participants were used (effective rate=91.9\%).

Methods An ordinary least squares model was used to evaluate the association between social capital and health. Social capital included family trust, friend/neighbour trust, stranger trust, social participation, and network size and density. Health outcomes included basic and instrumental activities of daily living (BADL and IADL) and depression. Results Elevated family trust, friend/neighbour trust, stranger trust, high-level participation and middlelevel network density were associated with reduced depression $(b=-3.23, p<0.001 ; b=-0.41, p<0.001$; $b=-0.76, p<0.01 ; b=-1.04, p<0.05 ; b=-0.74, p<0.05$, respectively). High-level participation and network density were also associated with elevated BADL $(b=0.16, p<0.05$; $b=0.24, p<0.05$, respectively). Elevated family trust ( $b=-2.86, p<0.05$ in men; $b=-3.86, p<0.001$ in women), stranger trust $(b=-0.68, p<0.05$ in men; $b=-0.80, p<0.05$ in women) and high-level participation $(b=-0.92, p<0.05$ in men; $b=-1.22, p<0.01$ in women) were associated with reduced depression in both sexes. By contrast, elevated friend/neighbour trust was associated with reduced depression $(b=-0.56, p<0.001)$ in women, high-level participation was associated with elevated BADL $(b=0.19$, $\mathrm{p}<0.05)$ and IADL $(b=0.43, p<0.05)$ in men, and highlevel network density was associated with elevated BADL $(b=0.44, p<0.05)$ and IADL $(b=0.57, p<0.05)$ and reduced depression $(b=-1.05, p<0.05)$ in women.

Conclusions Social capital is closely related to leftbehind older adults' health in rural China. More attention should be paid to increasing the stock of social capital in this special population, with a particular focus on the sex disparity.

\section{INTRODUCTION}

China has witnessed dramatic economic and social changes, as well as a rapid rise in the number of ageing individuals, over the past several decades. By the end of 2016, people

\section{Strengths and limitations of this study}

This is the first study to evaluate the association between social capital and health by sex in left-behind older adults in rural China.

- Social capital was more strongly related to depression than to basic and instrumental activities of daily living in left-behind older adults in rural China.

- A significant sex disparity in the association between social capital and health was observed.

- The causal association between social capital and health, as well as the relationship between contextual social capital and health, was not examined.

aged 60 and older accounted for $16.7 \%$ of the total population in China. ${ }^{1}$ The rapid development of urbanisation has attracted tens of millions of rural labourers to work in cities, which results in an increase in the number of left-behind older adults in rural China. Leftbehind older adults usually refer to older adults aged 60 and older living in rural areas whose children work in other areas (usually cities) and do not live with them. ${ }^{2}$ Currently, there are more than 40 million left-behind older adults in rural China, and this number may increase in the foreseeable future. ${ }^{3}$

Since the 1990s, the association between social capital, which comes from social connections in our daily lives, ${ }^{4}$ and health has been widely discussed, ${ }^{56}$ and it has been observed to be positive in numerous studies. ${ }^{7-9}$ However, limited studies examine this association in older adults, especially in left-behind older adults in rural China. ${ }^{10} 11$ The poor health status of left-behind older adults has been reported and has received much attention. ${ }^{2312}$ With their children working in cities most of the time and living far away, leftbehind older adults cannot obtain enough support from them, which results in the loss of social connections and economic and mental instability. ${ }^{3}$ Some evidence indicates that both the physical and mental health of left-behind older adults are poorer than those 
of other older adults. ${ }^{2}{ }^{13}$ Furthermore, the sex disparity in health is widely discussed. It is recognised that men usually have a lower level of life expectancy but better perceived health than women do, ${ }^{14}$ and the sex disparity in the association between social capital and health is also observed in other studies. ${ }^{15} 16$ However, no sex disparity in this association has been examined in left-behind older adults.

Therefore, this study aimed to answer two questions. First, was there an empirical association between social capital and left-behind older adults' health in rural China? Second, was there a sex disparity in the empirical association above?

\section{Definition and measures of social capital}

Numerous views on the definition of social capital have been proposed, among which Putnam's communitarianism is considered the most influential in the area of public health. ${ }^{5}$ Putnam ${ }^{1718}$ considered social capital to be a kind of social structure and emphasised the collective attributes of it as well as its power on individual actors from the perspective of cohesion. Accordingly, trust, social networks and participation are the most widely used measures of social capital in the area of public health. ${ }^{5} 19$ Trust is a sense of confidence or expectation generated from the belief that others will behave decently and predictably, ${ }^{20}{ }^{21}$ which is the most widely used measure of social capital in public health. Social networks refer to social contacts among individuals, which is a stable system formed through social interactions. Social participation refers to engagement in formal or informal associations or activities. ${ }^{18} 22$ It is recognised that social capital consists of cognitive and structural components, such that trust pertains to the former, whereas social networks and participation pertain to the latter. ${ }^{51723}$ Furthermore, the framework in which social capital can be divided into bonding and bridging forms has also been widely used in the area of public health. ${ }^{5}$ Bonding social capital means a kind of inward social connection among individuals within homogeneous groups, while bridging social capital refers to an extroverted social connection among members from heterogeneous groups. ${ }^{17} 1824$ Accordingly, trust, social networks and participation were used as measures of social capital in this study.

\section{Social capital and health in older adults}

Limited studies are available on the association between social capital and health in older adults. Pollack et $a l^{10}$ examined the association between social capital and older adults' health in the USA and Germany and reported that low-level reciprocity, trust and social participation were related to poor self-rated health (SRH) and elevated depression, but were not associated with physical function. Most studies conducted in Europe and Asia also observe an association between social capital and health in older adults. For example, evidence from Northern Europe shows that structural social capital, including social contacts with neighbours/friends, was related to older adults' decreased depression, because contacts with others provide access to resources and support and generate mutual benefits. ${ }^{25}$ For cognitive social capital, trust among friends ${ }^{25}$ is observed to be positively related to older adults' psychological health, while general trust $^{26}$ and trust among neighbours ${ }^{25}$ are not related to their psychological health. Evidence from Japan indicates that elevated social participation is associated with elevated functional capacity in older adults, ${ }^{27}$ and a wellstructured social network is negatively related to older adults' mortality. ${ }^{2829}$ By contrast, trust and norms of reciprocity are not associated with mortality. ${ }^{28}$ Furthermore, cognitive social capital, including trust and norms of reciprocity, is also observed to be positively related to older adults' SRH $^{30}$ and mental health, ${ }^{31}$ but an elevated social network is more likely to be associated with better mental health than with better SRH among older adults. ${ }^{32}$

Studies on social capital and older adults' health in China are also limited. Based on the Chinese General Social Survey, Norstrand and $\mathrm{Xu}^{11}$ argued that bonding trust and bonding networks were positively associated with older adults' physical and mental health in urban China, but rural older adults did not obtain health returns from bonding trust and networks. The norm of reciprocity was not related to the health of older adults across China. Based on the China Health and Retirement Longitudinal Study, Xue and $\mathrm{Liu}^{33}$ found that participation in social activities significantly promoted the SRH of older adults. Using an instrumental variable approach, Liu $e t a l^{34}$ also observed that elevated social participation was causally associated with better SRH and physical health; however, Shen $e t a l^{35}$ observed that only perceived help was related to better SRH, and the social network was not related to the SRH of older adults in China.

What we should notice is the sex disparity in the association between social capital and health among the older adults. It is observed that trust is not related to female older adults' health. For example, Chemaitelly et al argued that although social networks, trust and norms of reciprocity were positively associated with older adults' $\mathrm{SRH}$, elevated trust in older women was not related to better SRH. ${ }^{15}$ Furthermore, Aida $e t a l^{28}$ proposed that elevated social trust might reduce the physical health of older women. ${ }^{28}$ In China, Xue and Liu proposed that participation in social activities had a stronger promoting effect on the SRH of older female adults; ${ }^{33}$ Sun et $a l^{6}$ also proposed that although social capital was associated with better physical and mental health of older adults of both sexes, the positive association between social capital and mental health was stronger in older women in rural China. Accordingly, the sex disparity in the association between social capital and older adults' health has not yet been fully established and requires further discussion.

In summary, it is evident that studies on the association between social capital and the health of rural older adults in China are limited, and only one study has examined this association in left-behind older adults. ${ }^{36}$ However, multiple health outcomes should be examined in older 
adults when discussing this issue, and the potential sex disparity in this association should also be examined. Leftbehind older adults have unique life experiences that are quite different from those of other older adults. ${ }^{3}$ Studies on the association between social capital and the health of left-behind older adults in rural China have important policy implications in improving the well-being of this vulnerable group. Hence, this study aimed to examine the association between social capital and the health of left-behind older adults in rural China.

\section{DATA AND METHODS}

\section{Data source}

The data used in this study were obtained from a field cross-sectional survey conducted in five counties/cities in China, including Yingcheng County and Mian County in July 2017, as well as Lechang City, Jieyang City, Suixi County in August 2018. Yingcheng County is located in the central area of Hubei Province, with a per capita gross domestic product (GDP) of $¥ 39019$ and a population of 666000 in 2016. Mian County is located in the south-west corner of Shaanxi Province, with a per capita GDP of $¥ 26$ 153 and a population of 426000 in 2014. Lechang City is located in the northern area of Guangdong Province, with a per capita GDP of $¥ 19952$ and a population of 521 000 in 2017. Jieyang City is located in the eastern area of Guangdong Province, with a per capita GDP of $¥ 35327$ and a population of 6086000 in 2017. Suixi County is located in the south-west corner of Guangdong Province, with a per capita GDP of $¥ 23761$ and a population of 1 039000 in 2017. Considering the regional differences in socioeconomic development, the above three provinces were randomly selected as representative of Eastern, Central and Western China, as Chinese internal migrants usually move from Central and Western China to eastern China across provinces, and move from villages and small cities to provincial capitals within specific provinces. (According to the data of China Statistical Yearbook 2018, the proportion of older adults is $7.8 \%, 12.2 \%$ and $11.1 \%$ in Guangdong, Hubei and Shaanxi provinces, respectively, in 2017. The ageing level in Guangdong Province is lower than that of the other regions due to the influx of workers to Pearl River Delta region, and the ageing level in Hubei and Shaanxi provinces is higher. There are also numerous rural labourers working out in all five counties/cities, suggesting that these areas are nationally representative more or less.)

In the present study, rural adults aged 60 or older with all children working in urban areas were defined as leftbehind older adults. Simple random sampling, convenience sampling and cluster sampling methods were used in the present study. More specifically, since we could not obtain the total composition of left-behind older adults (such as age and sex) in rural China, we used random sampling, convenience sampling and cluster sampling methods at different stages of the survey. First, the random number table was used to randomly select one province in each of the three different regions (Eastern China, Central China and Western China). Second, as the level of homogeneity across different counties/cities within a province or different towns/villages within a county/city was high, the convenience sampling method was considered to be acceptable in ensuring the representativeness and made the survey more feasible; thus, based on the principle of easy access to the survey sites, we contacted the counties/cities that could assist in carrying out the survey, mainly relying on personal social networks. Finally, with the assistance of local officials, a reliable list provided by local officials was used to reduce the selection bias when a cluster sampling method was used to investigate individuals in villages; furthermore, a door-to-door investigation was conducted, and trained interviewers knocked on doors or gathered left-behind older adults in village committees for face-to-face interviews. A total of 1106 questionnaires were distributed and collected, and no respondent refused to be interviewed (the questionnaire can be found in online supplementary file 1). Finally, questionnaires with more than $20 \%$ unanswered questions were not included in the analysis (mainly due to physical reasons, such as hearing and cognitive impairment). Thus, a total of 90 questionnaires were excluded, and the data used in this study were obtained from 1016 questionnaires, which accounted for 91.9\% of the questionnaires collected. (Questionnaires excluded in the analysis were those with many questions (more than 20\%) unanswered. Since the missing rate is $8.1 \%$ (less than 10\%), we do not think it yields a significant bias for our analysis. The final sample size was 1016 , indicating a large sample survey, so it was not likely for the statistical power to be low.)

\section{Patient and public involvement}

This study did not involve patients in setting the research question, design of the study, or recruitment to and conduct of the study. The dissemination of the results will include communication channels that will involve local communities.

\section{Variables}

Social capital

Three components of social capital, namely trust (cognitive), social participation (structural) and social networks (structural), were used. The reliability ( $\alpha$ coefficient) was not reported, as participation and networks were defined in a formative not a reflective way; trust was encompassed by three independent variables, and they pertained to different forms of social capital (bonding and bridging). Trust encompassed trust in family members, neighbours, friends and strangers, and the response options included the following: ' $0=$ very distrustful, $1=$ relatively distrustful, $2=$ relatively trustful, $3=$ very trustful'. Trust in family members and strangers was treated as family trust (bonding) and stranger trust (bridging), respectively, with 'very distrustful' and 'relatively distrustful' recoded as 'distrustful' and 'relatively trustful' and 'trustful' 
recoded as 'trustful'; trust scores for neighbours and friends were added and conceptualised as friend/neighbour trust (bonding). It is highlighted that, according to the Chaxu pattern, the interpersonal pattern of Chinese residents is similar to the ripple that opens wide on the water surface. ${ }^{37}$ Thus, although family trust and friend/ neighbour trust were forms of bonding social capital according to Putnam's definition, ${ }^{17}$ they were considered to be two different social capital variables in this study, as family members are blood ties, while friends and neighbours are not blood ties.

Social participation included participation in chess activities, collective fitness activities, gathering/chatting, organisation activities and other activities $(0=$ not participated, 1 =participated), and they were added to measure the level of social participation; subsequently, participating in no activity was recoded as low-level participation, participating in only one activity was recoded as middlelevel participation, and participating in more than one activity was recoded as high-level participation.

Social network consisted of network size and network density. Network size was determined by the number of close friends (ranging from 0 to 10 ); the weekly frequency of interactions with friends (ranging from 0 to 7 ) in the past year, both online and offline, was added to measure network density. For the network density, no interaction per week was recoded as low-level network density, less than seven interactions per week was recoded as middlelevel network density, and seven or more interactions per week was recoded as high-level network density.

\section{Health outcomes}

Health outcomes consisted of physical and psychological health. Physical health included basic activities of daily living (BADL) ${ }^{38}$ and instrumental activities of daily living (IADL) ${ }^{39}$ BADL referred to the ability to eat, walk, visit friends, dress and bathe, and the response options for each item included the following: ' $0=$ completely depend on others, $1=$ partly depend on others and $2=$ do not depend on others completely'. Five items were added to measure BADL. IADL referred to the capacity to cook, shop, clean and take a bus, and the response options for each item included the following: ' $0=$ completely depend on others, 1=partly depend on others and 2=do not depend on others completely'. Four items were added to measure IADL. The Life Satisfaction Index Scale was used to measure depression, a psychological health indicator, ${ }^{40}$ and the response options for each item included the following: ' $0=$ not depressed and $1=$ depressed'. Subsequently, a total of 12 indices were added to measure depression. Details are displayed in table 1.

\section{Control variables}

Control variables included sex, age, marital status, education, family income (a natural logarithmic transformation was performed), living status (whether living with other people or not) and province. More details are provided in table 2.
Table 1 Measures of health of left-behind older adults in rural China in 2017-2018 ( $\mathrm{N}=1016)$

\begin{tabular}{|c|c|c|c|}
\hline Health & Indicators & Range & $\begin{array}{l}\text { Reliability } \\
\alpha\end{array}$ \\
\hline \multirow[t]{5}{*}{ BADL } & Ability to eat independently & $0-2$ & 0.879 \\
\hline & Ability to walk independently & $0-2$ & \\
\hline & $\begin{array}{l}\text { Ability to visit friends } \\
\text { independently }\end{array}$ & $0-2$ & \\
\hline & Ability to dress independently & $0-2$ & \\
\hline & Ability to bathe independently & $0-2$ & \\
\hline \multirow[t]{4}{*}{ IADL } & Ability to cook independently & $0-2$ & 0.873 \\
\hline & Ability to shop independently & $0-2$ & \\
\hline & Ability to clean independently & $0-2$ & \\
\hline & $\begin{array}{l}\text { Ability to take a bus } \\
\text { independently }\end{array}$ & $0-2$ & \\
\hline \multirow[t]{12}{*}{ Depression } & $\begin{array}{l}\text { Are you satisfied with your } \\
\text { life? }\end{array}$ & $0-1$ & 0.839 \\
\hline & $\begin{array}{l}\text { Do you continue to pursue } \\
\text { hobbies? }\end{array}$ & $0-1$ & \\
\hline & $\begin{array}{l}\text { Do you have a sense of life } \\
\text { enrichment? }\end{array}$ & $0-1$ & \\
\hline & Do you feel upset? & $0-1$ & \\
\hline & Do you feel good in spirits? & $0-1$ & \\
\hline & $\begin{array}{l}\text { Do you have a sense of } \\
\text { insecurity? }\end{array}$ & $0-1$ & \\
\hline & Do you feel happy? & $0-1$ & \\
\hline & $\begin{array}{l}\text { Do you have a sense of } \\
\text { loneliness? }\end{array}$ & $0-1$ & \\
\hline & Do you feel good to be alive? & $0-1$ & \\
\hline & $\begin{array}{l}\text { Do you have a sense of } \\
\text { unworthiness? }\end{array}$ & $0-1$ & \\
\hline & Do you feel energetic? & $0-1$ & \\
\hline & Do you feel hopeless? & $0-1$ & \\
\hline
\end{tabular}

A total of 15 items were used to measure depression in the questionnaire, and 3 of them were excluded in the analysis because their single-item reliability $\alpha$ was less than 0.800 . BADL, basic activities of daily living; IADL, instrumental activities of daily living.

\section{Methods}

Cronbach's $\alpha$ coefficient was used to assess the internal consistency of specific health outcomes, and Cronbach's $\alpha>0.60$ was used as the criterion to ensure reliability. ${ }^{42}$ $\chi^{2}$ tests and t-tests were used to examine whether the sex differences in different variables were statistically significant. Although all three health outcomes were ordinary variables, the parallel-lines assumption was not supported in ordinal regression. Therefore, ordinary least squares (OLS) model was used to examine the association, in both sexes and by sex, between various forms of social capital and different health outcomes of left-behind older adults in rural China. This strategy, which treats ordinal outcome as continuous outcomes, is supported and widely used in many other studies. ${ }^{9} 34$ According to previous 


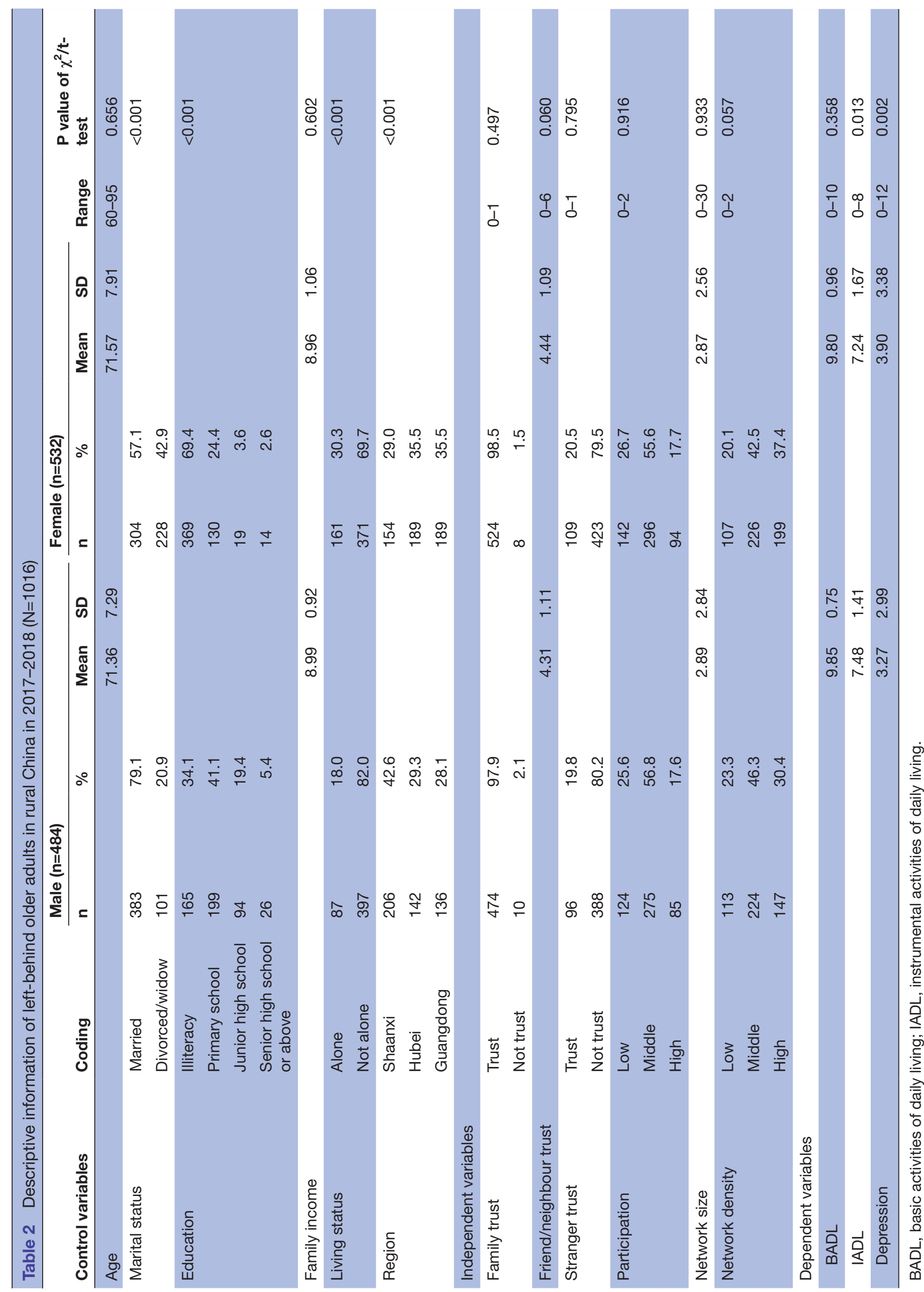


studies, there might be sex disparities in the association between social capital and health in older adults. ${ }^{16} 2833$ Thus, stratification by sex was used, and men and women were analysed separately to compare the sex disparity in the association between social capital and health in leftbehind older adults. The model specification of OLS was as follows:

Health $_{i}=\beta_{0}+\sum_{1}^{p}\left(\beta_{p} *\right.$ control variable $\left.e_{i}\right)+\sum_{1}^{k}\left(\beta_{k} *\right.$ social capital $\left._{i}\right)+\varepsilon_{i}$

where Health $h_{i}$ represented the health outcome of individual $i ; \beta_{0}$ represented the intercept; $\beta_{p}$ represented the estimated coefficients of variables controlled for $(p=1-8$ in full samples and 1-7 in male or female samples); $\beta_{k}$ represented the estimated coefficients of social capital variables $(k=1-6)$; and $\varepsilon_{i}$ represented the residual error of the model.

SPSS V.21.0 was used to perform OLS models; robust standard error (SE) was used to adjust for potential heteroscedasticity, given that a cluster sampling method was used to interview respondents within villages. Statistical significance was assumed if $\mathrm{p}<0.05$.

\section{RESULTS}

\section{Descriptive analysis}

Table 2 describes the sample of 1016 participants, consisting of 484 men and 532 women. Compared with men, women seemed to have a higher level of depression $(\mathrm{p}=0.002)$ and a lower level of IADL $(\mathrm{p}=0.013)$, but also had slightly higher levels of friend/neighbour trust $(p=0.060)$ and network density $(p=0.057)$. Furthermore, compared with men, women in the sample seemed to be less educated $(p<0.001)$, less likely to be married $(\mathrm{p}<0.001)$ and less likely to live with others $(\mathrm{p}<0.001)$.

\section{Social capital and BADL}

Associations between social capital and the BADL of left-behind older adults in rural China are presented in table 3. With other variables controlled for, compared with low-level social participation and network density, high-level social participation and network density were associated with elevated BADL $(b=0.16, p<0.05 ; b=0.24$, $\mathrm{p}<0.05$, respectively). However, the association between high-level social participation and elevated BADL was observed in men only $(b=0.19, p<0.05)$, and the association between middle-level or high-level network density and elevated BADL was observed in women only $(b=0.52$, $\mathrm{p}<0.05 ; \mathrm{b}=0.44, \mathrm{p}<0.05$, respectively). Furthermore, no significant association was observed between other forms of social capital, including family trust, friend/neighbour trust, stranger trust and network size, and the BADL of left-behind older adults in all three models.

\section{Social capital and IADL}

Associations between social capital and the IADL of left-behind older adults in rural China are presented in table 4 . With other variables controlled for, no significant association was observed between social capital and IADL. However, a significant sex disparity in the association between social capital and IADL was observed. For older men, only high-level social participation was associated with elevated IADL $(b=0.43, p<0.05)$. By contrast, compared with low-level network density, middle-level and high-level network density were associated with elevated IADL in older women only $(b=0.61, p<0.05$; $\mathrm{b}=0.57, \mathrm{p}<0.05$, respectively).

\section{Social capital and depression}

Associations between social capital and the depression of left-behind older adults in rural China are presented in table 5. With other variables controlled for, elevated family trust, friend/neighbour trust, stranger trust, high-level social participation and middle-level network density were associated with reduced depression $(b=-3.23, p<0.001 ; b=-0.41, p<0.001 ; b=-0.76, p<0.01$; $\mathrm{b}=-1.04, \mathrm{p}<0.001 ; \mathrm{b}=-0.74, \mathrm{p}<0.05$, respectively). A significant sex disparity in the association between social capital and depression was also observed. For older men, elevated family trust and stranger trust and high-level social participation were associated with reduced depression $(b=-2.86, p<0.05 ; b=-0.68, p<0.05 ; b=-0.92, p<0.05$, respectively). By contrast, for older women, elevated family trust, friend/neighbour trust and stranger trust, as well as high-level social participation and middle-level network density, were associated with reduced depression $(b=-3.86, p<0.001 ; b=-0.56, p<0.001 ; b=-0.80, p<0.05$; $\mathrm{b}=-1.22, \mathrm{p}<0.01 ; \mathrm{b}=-1.05, \mathrm{p}<0.05$, respectively).

\section{DISCUSSION}

With the recent rapid urbanisation in China, the number of left-behind older adults in rural China is on the rise. For this reason, studies on the association between social capital and health in left-behind older adults have substantial and theoretical significance. Based on a cross-sectional survey conducted in Hubei, Shaanxi and Guangdong provinces in China in 2017-2018, this is the first study to discuss the association between social capital and the health of left-behind older adults by sex in rural China.

A higher level of social participation is associated with better physical health, especially better BADL. Social participation usually increases physical activities and keeps left-behind older adults healthy, and older adults with poor physical health are also less likely to engage in social activities. ${ }^{43}$ Furthermore, the positive association between participation and physical health is statistically significant in men only, because social participation is usually a major activity among men in China. That is, in China, men are usually in charge of outdoor affairs, and women are usually in charge of indoor affairs. ${ }^{33}$ Furthermore, compared with women, men's participation usually includes more instrumental values and brings more 
Table 3 Social capital and BADL of left-behind older adults in rural China in 2017-2018 (N=1016)

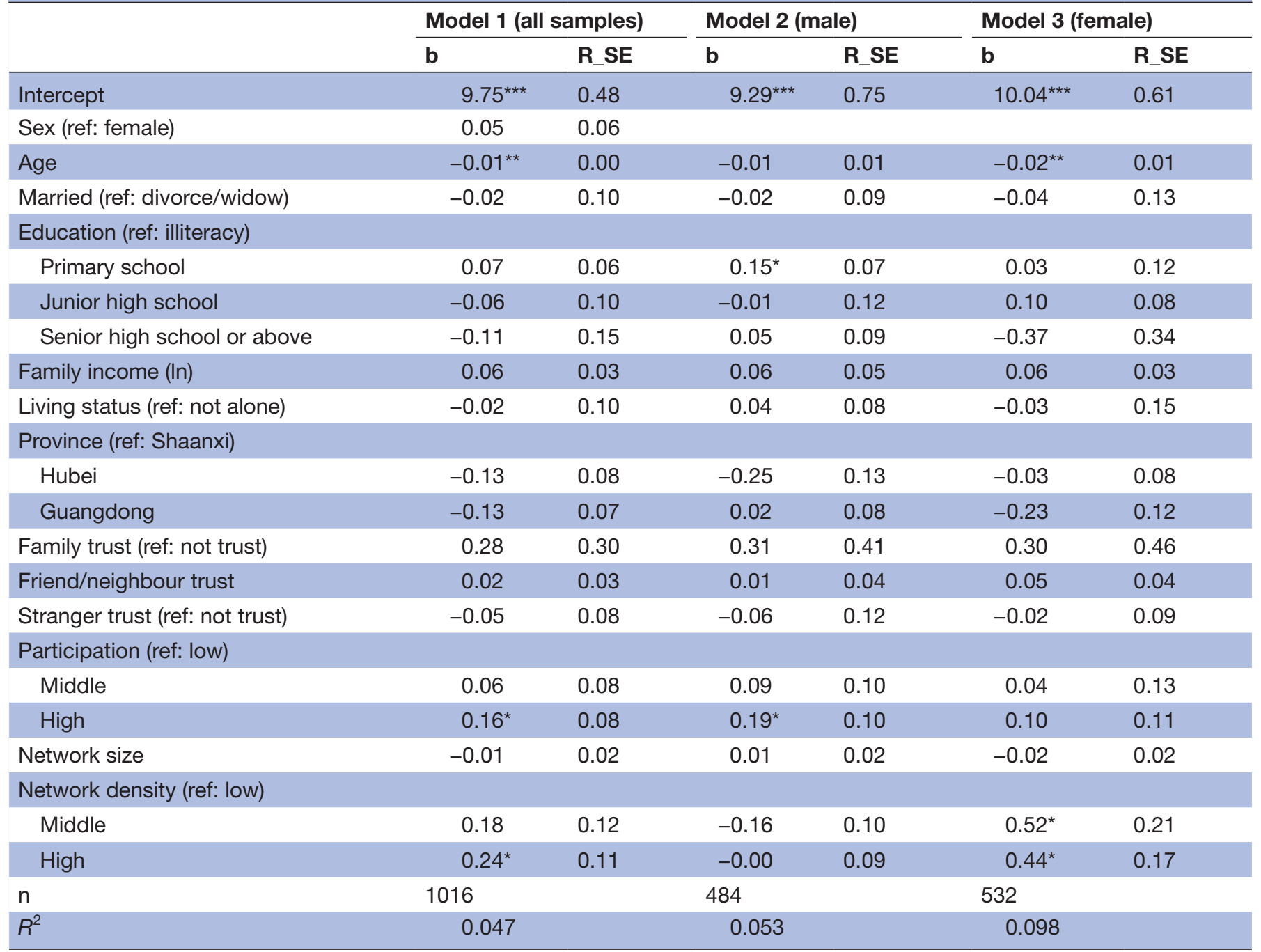

${ }^{* \star *} \mathrm{P}<0.001,{ }^{* *} \mathrm{P}<0.01,{ }^{*} \mathrm{P}<0.05$.

b, coefficient; BADL, basic activities of daily living; ref, reference; R_SE, robust SE.

material benefits. ${ }^{44}$ Thus, older men obtain more physical health benefits from social participation.

A higher level of density of social networks is observed to be related to better physical health of rural left-behind older adults, but no association is observed between social network size and the two physical health outcomes. That is, for left-behind older adults, having high-quality social networks or many friends is not associated with physical health itself; rather, the mere presence of any social network (contact with friends) is what matters with respect to physical health. These results are in line with related evidence from Japan and Northern Europe. 252829 Furthermore, older women benefit more from contact with others, potentially because older women have a higher level of network density than older men do (see table 2).

Most elevated social capital indicators are associated with better psychological health of left-behind older adults in rural China. Social trust reflects confidence and positive psychological expectation from others, ${ }^{21}$ so it helps reduce depression and improve perceived psychological health. Participating in various social activities provides left-behind older adults with a platform to communicate with others and reduces the possibility of depression. Contact with friends directly increases affective interactions and the sense of belonging, thus reducing mental health problems. However, in the comparison between men and women, it is observed that most social capital indicators, including family trust, friend/neighbour trust, stranger trust, social participation and network density, are more strongly related to female psychological health, which is similar to the results of Sun et al. ${ }^{16}$ Compared with men, women are more likely to seek support and mobilise support resources (especially emotional support) from others and navigate emotional changes with greater ease. ${ }^{16} 45$ Furthermore, women have higher levels of some social capital indicators (see table 2), which also brings them more health benefits. Thus, older women receive more psychological health returns from support resources from others. 
Table 4 Social capital and IADL of left-behind older adults in rural China in 2017-2018 (N=1016)

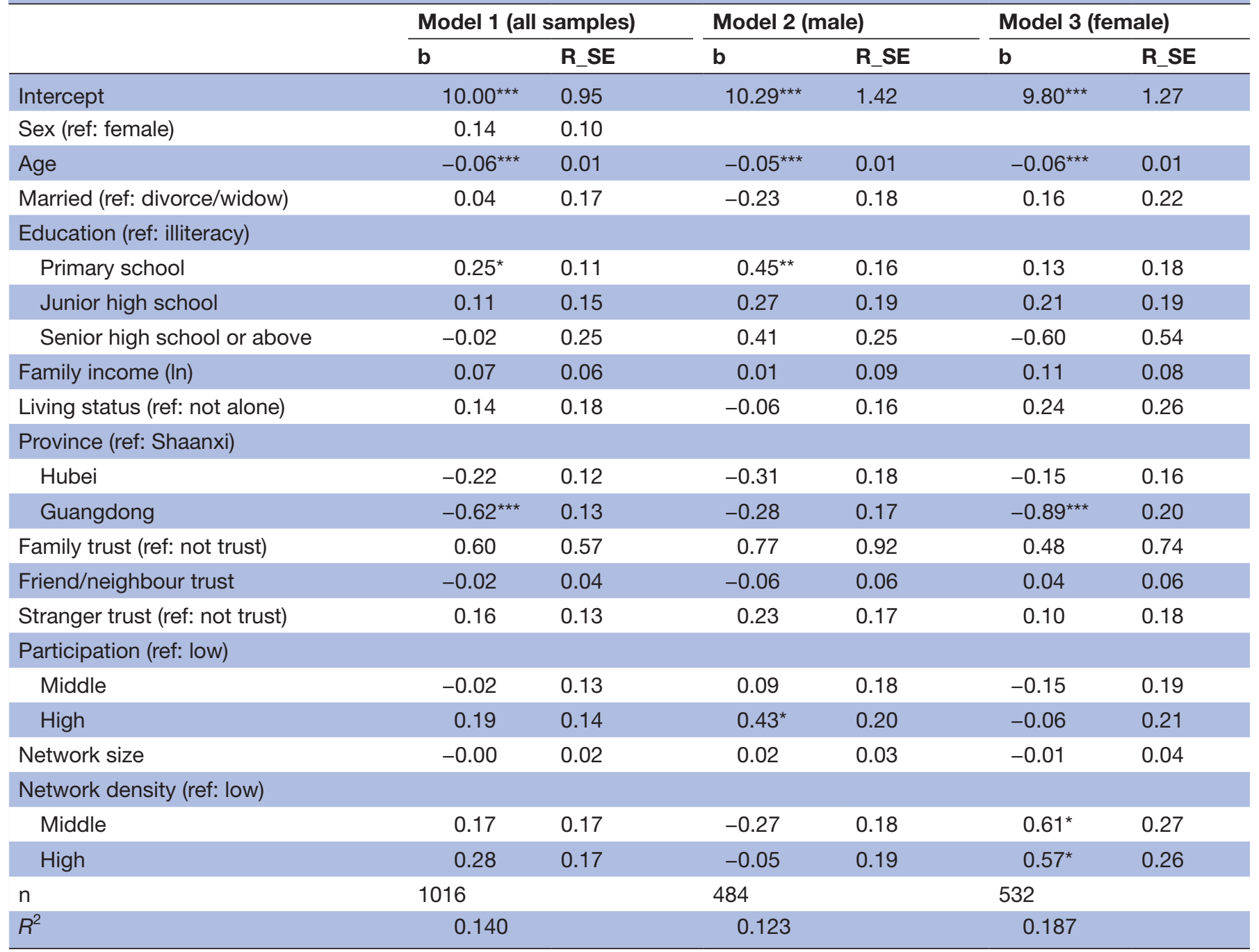

${ }^{* \star *} \mathrm{P}<0.001,{ }^{* *} \mathrm{P}<0.01,{ }^{*} \mathrm{P}<0.05$.

b, coefficient; IADL, instrumental activities of daily living; ref, reference; R_SE, robust SE.

Based on the above results, several interventions to improve the stock of social capital in left-behind older adults in China are proposed. First, primary-level organisations should stress daily collective activities for leftbehind older adults, especially female older adults. Senior centres should be built to provide left-behind older adults with a platform to engage in social activities, which allows them to increase social interactions and benefits their health. Second, the children of left-behind older adults are encouraged to take good care of their parents, as they need to resolve difficulties through both material rewards and spiritual rewards. Finally, village committees should take responsibility for developing a healthy neighbourhood relationship, which can improve the level of trust in left-behind older adults and, in turn, improve their psychological health.

There are several limitations to this study. First, this is a cross-sectional study and current results for the association between social capital and health cannot be explained as causal, so further studies using longitudinal data and causal inference approaches are needed. Second, because the populations evaluated are from different villages, it is likely that the characteristics of those villages may have a contextual effect on the association between social capital and health. ${ }^{30}$ However, this contextual effect was found to be statistically non-significant in this study (the $p$ value of the intraclass correlation coefficient was larger than $0.05)$. Thus, the macrolevel effect of the villages where these older adults live is not reported in this study, and further studies on this topic are needed.

\section{CONCLUSIONS}

This is the first study to discuss the association between social capital and the physical/psychological health of left-behind older adults, as well as the sex disparity in this association, in rural China. The results show that in left-behind older adults, multiple forms of social capital were associated with health outcomes, but cognitive social capital was associated with depression only. Furthermore, 
Table 5 Social capital and depression of left-behind older adults in rural China in 2017-2018 (N=1016)

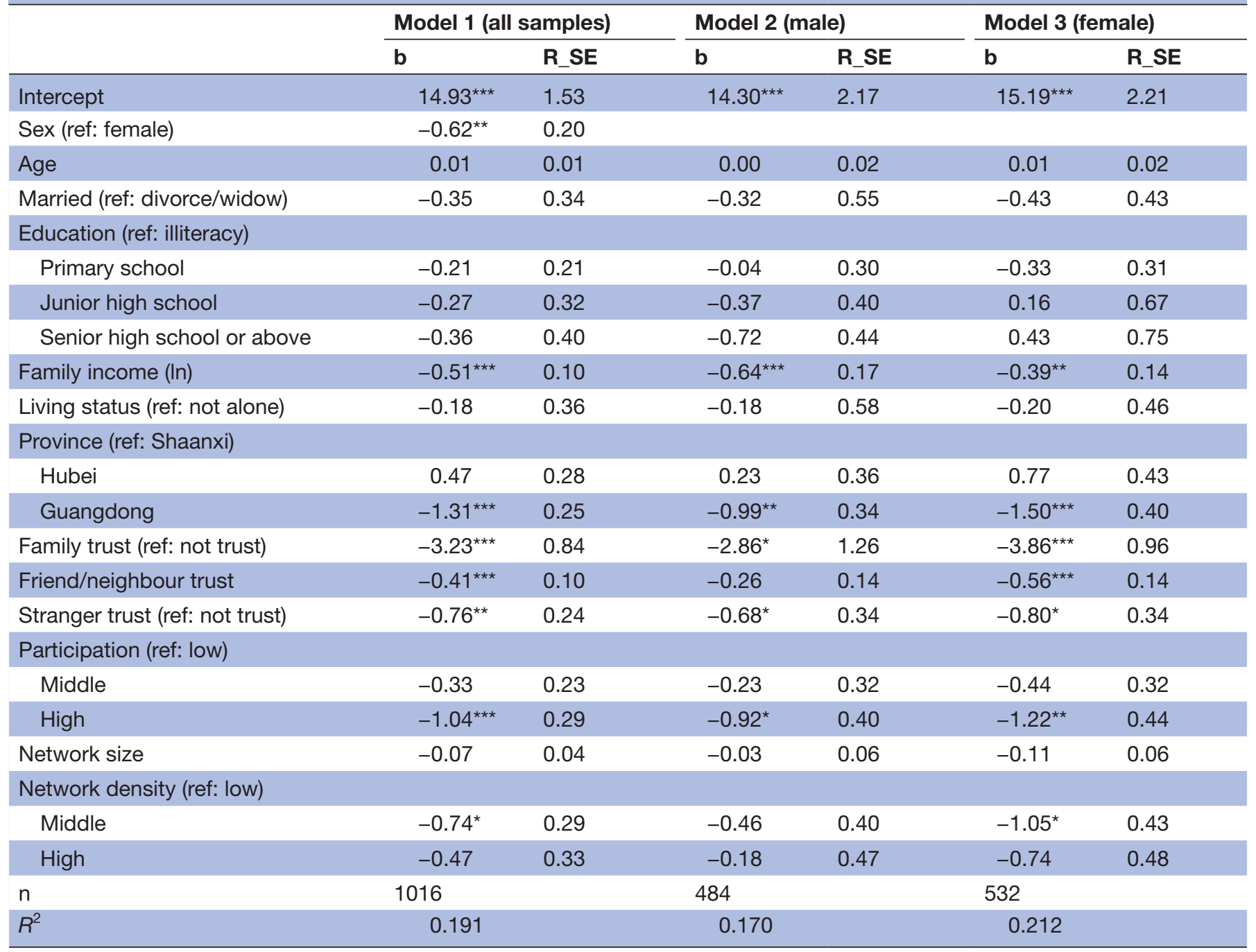

${ }^{\star \star *} \mathrm{P}<0.001,{ }^{* \star} \mathrm{P}<0.01,{ }^{*} \mathrm{P}<0.05$.

b, coefficient; ref, reference; R_SE, robust SE.

a significant sex disparity in the association between social capital and health in left-behind older adults was also observed. According to these results, interactions should be encouraged between older adults and their family members or neighbours/friends to build trust, and senior centres should be built to provide left-behind older adults with a platform for social participation and interaction in rural China.

Acknowledgements We thank all the participants in the survey. We especially appreciate the valuable effort made by Qihong Wang from Bank of America.

Contributors JJ and YK designed the study. YC and YK collected the data. JJ, YC and YK all wrote, revised and reviewed the manuscript.

Funding This study is supported by the National Social Science Fund: Researches on the quality of life of rural left-behind older adults in the setting of aging (No 16BRK014).

Patient consent for publication Not required.

Ethics approval We declare that this study complied with ethical standards. Wuhan University of Science and Technology grants ethical approval for this study.

Provenance and peer review Not commissioned; externally peer reviewed.
Data availability statement No data are available.

Open access This is an open access article distributed in accordance with the Creative Commons Attribution Non Commercial (CC BY-NC 4.0) license, which permits others to distribute, remix, adapt, build upon this work non-commercially, and license their derivative works on different terms, provided the original work is properly cited, appropriate credit is given, any changes made indicated, and the use is non-commercial. See: http://creativecommons.org/licenses/by-nc/4.0/.

ORCID iD

Junfeng Jiang http://orcid.org/0000-0001-6065-1591

\section{REFERENCES}

1 NBS P. Statistical bulletins on national economic and social development of people's Republic of China, 2016. Available: http:// www.stats.gov.cn/2017

2 Xie J-fei, Ding S-qing, Zhong Z-qing, et al. Mental health is the most important factor influencing quality of life in elderly left behind when families migrate out of rural China. Rev Lat Am Enfermagem 2014;22:364-70.

3 Song Y. Mental support or economic giving: migrating children's elderly care behavior and health conditions of left-behind elderly in rural China. Population \& Development 2014;20:37-44. 
4 Lin N. Social capital: a theory of social structure and action. New York: Cambridge University Press, 2001.

5 Kawachi I, Subramanian SV, Kim D. Social capital and health. New York: Springer, 2008.

6 Kawachi I, Takao S, Subramanian SV. Global perspectives on social capital and health. New York: Springer, 2013

7 Kawachi I, Kennedy BP, Glass R. Social capital and self-rated health: a contextual analysis. Am J Public Health 1999;89:1187-93.

8 Ferlander S. The importance of different forms of social capital for health. Acta Sociol 2007;50:115-28.

9 Meng T, Chen H. A multilevel analysis of social capital and self-rated health: evidence from China. Health Place 2014;27:38-44.

10 Pollack CE, von dem Knesebeck O, Ovd K. Social capital and health among the aged: comparisons between the United States and Germany. Health Place 2004;10:383-91.

11 Norstrand JA, Xu Q. Social capital and health outcomes among older adults in China: the urban-rural dimension. Gerontologist 2012;52:325-34.

$12 \mathrm{He} \mathrm{G}$, Xie J-F, Zhou J-da, et al. Depression in left-behind elderly in rural China: prevalence and associated factors. Geriatr Gerontol Int 2016;16:638-43.

13 Antman FM. Adult child migration and the health of elderly parents left behind in Mexico. Am Econ Rev 2010;100:205-8.

14 Zheng L, Zeng X. Gender differences in Ses and health gradient in China: a life course longitudinal study. Chin J Sociol 2016;36:209-37.

15 Chemaitelly $\mathrm{H}$, Kanaan $\mathrm{C}$, Beydoun $\mathrm{H}$, et al. The role of gender in the association of social capital, social support, and economic security with self-rated health among older adults in deprived communities in Beirut. Qual Life Res 2013;22:1371-9.

16 Sun X, LIU KUN, Webber M, et al. Individual social capital and health-related quality of life among older rural Chinese. Ageing Soc 2017;37:221-42.

17 Putnam RD. Bowling alone: the collapse and revival of American community. New York: Simon Schuster, 2000.

18 Putnam RD. Bowling alone: America's declining social capital. Journal of Democracy 1995;6:65-78.

19 Putnam RD. Social capital: measurement and consequences. Can J Policy Res 2001;2:41-51.

20 Fukuyama F. Trust: the social virtues and the creation of prosperity: Free press paperbacks 1995

21 Falk I, Kilpatrick S. What is social capital? A study of interaction in a rural community. Sociol Ruralis 2000;40:87-110.

22 Putnam RD. Bowling alone: democracy in America at the end of the twentieth century. New York: Cambridge University Press, 1996.

23 Nyqvist F, Pape B, Pellfolk T, et al. Structural and cognitive aspects of social capital and all-cause mortality: a meta-analysis of cohort studies. Soc Indic Res 2014;116:545-66.

24 Putnam RD. Tuning in, tuning out: the strange disappearance of social capital in America. PS 1995;28:664-83.

25 Forsman AK, Nyqvist F, Schierenbeck I, et al. Structural and cognitive social capital and depression among older adults in two Nordic regions. Aging Ment Health 2012;16:771-9.

26 Forsman AK, Nyqvist F, Wahlbeck K. Cognitive components of social capital and mental health status among older adults: a populationbased cross-sectional study. Scand J Public Health 2011;39:757-65.
27 Kondo N, Minai J, Imai H, et al. Engagement in a cohesive group and higher-level functional capacity in older adults in Japan: a case of the Mujin. Soc Sci Med 2007;64:2311-23.

28 Aida J, Kondo K, Hirai H, et al. Assessing the association between all-cause mortality and multiple aspects of individual social capital among the older Japanese. BMC Public Health 2011;11:499.

29 Brinkhues S, Dukers-Muijrers NHTM, Hoebe CJPA, et al. Socially isolated individuals are more prone to have newly diagnosed and prevalent type 2 diabetes mellitus - the Maastricht study -. BMC Public Health 2017;17:955.

30 Ichida $\mathrm{Y}$, Kondo K, Hirai $\mathrm{H}$, et al. Social capital, income inequality and self-rated health in Chita Peninsula, Japan: a multilevel analysis of older people in 25 communities. Soc Sci Med 2009;69:489-99.

31 Murayama H, Taguchi A, Ryu S, et al. Institutional trust in the National social security and municipal healthcare systems for the elderly in Japan. Health Promot Int 2012;27:394-404.

32 Murayama $\mathrm{H}$, Nishi M, Matsuo E, et al. Do bonding and bridging social capital affect self-rated health, depressive mood and cognitive decline in older Japanese? A prospective cohort study. Soc Sci Med 2013;98:247-52.

33 Xue X, Liu G, et al. Does social capital determine health status: evidencefrom China health and retirement longitudinal survey. Finance \& Trade Economics 2012;22:113-21.

34 Liu GG, Xue X, Yu C, et al. How does social capital matter to the health status of older adults? Evidence from the China health and retirement longitudinal survey. Econ Hum Biol 2016;22:177-89.

35 Shen Y, Yeatts DE, Cai T, et al. Social capital and self-rated health among middle-aged and older adults in China. Res Aging 2014;36:497-521.

36 Zhong Y, Schön P, Burström B, et al. Association between social capital and health-related quality of life among left behind and not left behind older people in rural China. BMC Geriatr 2017;17:e287.

37 Fei X. Rural China. Shanghai: Shanghai People‘s Publishing House 2007.

38 Fauth EB, Schaefer SY, Zarit SH, et al. Associations between fine motor performance in activities of daily living and cognitive ability in a nondemented sample of older adults: implications for geriatric physical rehabilitation. J Aging Health 2017;29:1144-59.

39 Park J, Lee YJ. Patterns of instrumental activities of daily living and association with predictors among community-dwelling older women: a latent class analysis. BMC Geriatr 2017;17:158.

40 Neugarten BL, Havighurst RJ, Tobin SS. The measurement of life satisfaction. J Gerontol 1961;16:134-43.

41 Silverman P, Hecht L, McMillin JD. Modeling life satisfaction among the aged: a comparison of Chinese and Americans. J Cross Cult Gerontol 2000;15:289-305.

42 Nunnally JC, Bernstein IH. Psychometric theory: McGraw-Hill 1994

43 Yang $\mathrm{H}$, Xiang $\mathrm{Y}$. Analysis on factors of the elderly social participation in rural Zhejiang. Zhejiang Social Sciences 2014:147-52.

44 Booth A. Sex and social participation. Am Sociol Rev 1972;37:183-93.

45 Zhou Z. Men are rational animals, women are emotional animals. Beijing: Beijing University of Technology Press, 2011. 